\title{
Sensory Processing Sensitivity and Adult Attachment in Emotional Regulation Difficulties
}

\section{Karina Salud Montoya-Pérez ${ }^{*}{ }^{\circledR}$, Roberto Montes-Delgado', José María de la Roca Chiapas², Rocío Montoya-Pérez ${ }^{3}$, Ferrán Padrós-Blázquez ${ }^{4}$}

${ }^{1}$ Facultad de Psicología, Universidad de Colima, Colima, México

${ }^{2}$ Departamento de Psicología, División de Ciencias de la Salud, Universidad de Guanajuato, Campus León, León, Guanajuato, México

${ }^{3}$ Instituto de Investigaciones Químico-Biológicas, Universidad Michoacana de San Nicolás de Hidalgo, Michoacán, México

${ }^{4}$ Facultad de Psicología, Universidad Michoacana de San Nicolás de Hidalgo, Michoacán, México

Email: *kaitamontoya@gmail.com

How to cite this paper: Montoya-Pérez, K. S., Montes-Delgado, R., de la Roca Chiapas, J. M., Montoya-Pérez, R., \& Padrós-Blázquez, F. (2021). Sensory Processing Sensitivity and Adult Attachment in Emotional Regulation Difficulties. Psychology, 12, 1848-1862. https://doi.org/10.4236/psych.2021.1211111

Received: October 16, 2021

Accepted: November 26, 2021

Published: November 29, 2021

Copyright (c) 2021 by author(s) and Scientific Research Publishing Inc. This work is licensed under the Creative Commons Attribution International License (CC BY 4.0).

http://creativecommons.org/licenses/by/4.0/

\begin{abstract}
Background: Approximately one-fifth of the world's population has a temperament trait called Sensory Processing Sensitivity (SPS), expressed as increased awareness to perceive subtle stimuli and high emotional reactivity. These people are more sensitive to the environment and parenthood, so the development of psychopathology may be due to insecure attachment in conjunction with high sensitivity, not only to high sensitivity. However, there is little information on how SPS interacts with attachment style concerning Emotional Regulation, whose alteration is considered the underlying mechanism that allows understanding and preventing psychopathology's emergence. Objective: This research's objective was to evaluate the importance of SPS and attachment styles as predictors of difficulties in emotional regulation (ERD). Method: 1050 university students participated. To determine the direct and indirect relationships of the independent variables, generalized linear models and structural equations were used. Results: Only anxious attachment was indirectly related to ERD through the SPS. SPS-attachment interaction seems to increase the probability of ERD compared to a low level of SPS regardless of attachment style. An anxious attachment was found to be the best predictor of ERD. Conclusions: Difficulties in regulating emotions in highly sensitive people are difficult to avoid, even with a secure attachment.
\end{abstract}

\section{Keywords}

Sensory Processing Sensitivity, Attachment, Attachment Style, Emotional Regulation Difficulties, Psychopathology 


\section{Introduction}

Approximately one-fifth of the world's population possesses a temperament trait called Sensory Processing Sensitivity (SPS) (Aron \& Aron, 1997), which gives people heightened awareness to perceive subtle stimuli, a potential to be overwhelmed by these, a low stimulation threshold and high emotional reactivity (Acevedo, 2020). They can also quickly identify the mood or emotional state of people and experience both pleasant and unpleasant emotions with intensity (Aron \& Aron, 1997; Aron et al., 2012; Greven et al., 2019; Homberg et al., 2016).

Recent studies have reported that people who possess this trait, also called Highly Sensitive People (HSP), exhibit higher neural activation in different brain regions (Naumann et al., 2020). Some areas are related to awareness, empathy and motor control in response to the emotions of the others (Acevedo et al., 2014; Acevedo et al., 2017). Others are associated with the integration of sensory information, higher cognitive processing, decision-making and complex tasks and, the response to changes subtle in the stimuli (Jagiellowicz et al., 2011). Due to this, HSP presents an increased awareness and higher preparation to respond to environmental stimuli, particularly to critical social situations, as well as a more elaborate sensory processing with greater attention to details and greater attention to subtleties (Acevedo et al., 2014; Acevedo et al., 2017; Jagiellowicz et al., 2011; Naumann et al., 2020).

Likewise, emotional regulation has gained significant interest in recent years because it is considered the variable whose impairment underlies various forms of psychopathology (Sloan et al., 2017) so it is necessary that it be considered as one of the key variables in treatment and prevention (Rehm \& Staiger, 2018). Previous research (Brindle et al., 2015) has reported that emotional regulation difficulties (ERD) mediate the relationship between SPS and negative affect.

Brindle et al. (2015) have pointed out that high sensitivity seems to interfere with emotional regulation strategies due to a greater awareness of emotional states and a tendency to be exposed to negative internal states, which is why it is more necessary to have conditions parenting skills to develop effective strategies.

In fact, SPS seems to mark differences in the degree of susceptibility to environmental influences, positive and negative (Greven et al., 2019; Greven \& Homberg, 2020; Slagt et al., 2017). When SPS interact with inappropriate parental behaviors causes psychological difficulties (Booth et al., 2015) and emotional alterations, such as depression or anxiety when there are low levels of care (Ahadi \& Basharpoor, 2010; Aron \& Aron, 1997; Aron et al., 2005) and high levels of overprotection (Liss et al., 2005). SPS appears to be an independent risk factor for experiencing psychological distress beyond interactions with parents (Liss et al., 2005). However, there is evidence that people with high sensitivity and quality parenting tend to respond more intensely to emotional stimuli, especially positive ones (Greven et al., 2019; Jagiellowicz et al., 2016), and can be significantly benefited by experiences that promote pleasant emotions (Greven et al., 2019; Pluess \& Boniwell, 2015). 
On the other hand, from the first studies on SPS, Aron and Aron (1997) observed that people with high sensitivity who had a happy childhood generally reported having been successful in the different areas of their lives. When answering a questionnaire on attachment styles, the majority showed a secure attachment. On the contrary, when the parental environment was poor, people with high sensitivity reported a much less happy childhood, social adjustment problems and personality problems in adulthood and, they tended to have an insecure attachment. For this reason, the development of neuroticism traits in these people is the result of insecure attachment inset with high sensitivity, rather than the consequence of high sensitivity alone (Aron \& Aron, 1997). Current reviews on the subject indicate that in adverse environments, highly sensitive individuals show a predisposition to the development of psychopathology, while in favorable environments, the favorable aspects of the trait tend to be expressed to a greater extent (e.g. Greven et al., 2019; Jagiellowicz et al., 2020).

Besides, attachment is an emotion regulation device that is activated when necessary to re-establish the feeling of protection or security in the face of the experience of danger, harm, or dejection (Mikulincer \& Shaver, 2016). According to the characteristics of the interaction with parents, provide or make it difficult to obtain the necessary elements for learning effective emotional regulation strategies (Mikulincer \& Shaver, 2012). Studies on attachment styles and psychopathology report that insecure and anxious styles are associated with more symptoms of psychopathology (e.g. Pascuzzo et al., 2015), while secure attachment has been related to fewer difficulties in emotional regulation (Guzmán et al., 2016), more adaptive strategies and constructive coping mechanisms (Cabral et al., 2012).

As a result, the present research starts from the idea that the SPS mediates the relationship between attachment style and ERD, amplifying the bonding experience. Therefore, the proposed hypothesis is that HSP with an insecure attachment style will show more significant ERD, putting them at a higher risk of developing psychopathology than those who are not highly sensitive and have the same attachment style. On the contrary, HSP with a secure attachment could develop more effective emotional regulation strategies and achieve adequate or higher adaptation levels than non-highly sensitive people with the same attachment style.

The relationship between SPS and attachment styles in emotional regulation difficulties remains unexplored, hence the relevance of conducting research in this regard. This study aims to: 1) evaluate the mediation of SPS between attachment style and ERD, 2) evaluate the differences in the level of ERD between SPS-attachment styles interactions and, 3) explore the role of SPS and attachment styles, as predictors of ERD.

\section{Method}

\subsection{Participants}

Using a non-probabilistic convenience sampling, the sample consisted of 1040 
university students, 666 (64\%) women and 374 (36\%) men between 18 and 28 years of age $(M=20.65, S D=1.92)$.

\subsection{Measures}

\section{Highly Sensitive Person Scale (HSPS)}

To assess SPS, a translated version of the HSPS (Aron \& Aron, 1997) was utilized (Montoya-Pérez et al., 2019). It is a self-report scale designed to measure the degree of sensitivity of adults. It consists of 17 items with Likert-type responses ranging from 1 not at all to 7 extremely, which are answered based on how the person feels. Examples: "Do you seem to be aware of subtleties in your environment?" "Are you easily overwhelmed by things like bright lights, strong smells, coarse fabrics, or sirens close by?" All items scored in the same direction, so the higher the score, the higher the sensitivity level. Principal components analysis suggested a solution of two factors that explained $30 \%$ of the variance: 1) Processed Sensitivity (PS) with 13 items and, 2) Low Sensory Threshold (LST) with 4 items. The reliability analysis reported an index $\alpha=.89$.

The authors of the HSPS explain that, since some items on the scale are involved with negative affect by trying to capture the experience of discomfort, especially in certain situations, it is advisable to consider this to determine the level of SPS and directly investigate the presence of neuroticism (Aron \& Aron, 2018). Because of this, the participants previously answered three questions that inquired about the presence of neuroticism: 1) Are you a tense or worried person by nature? 2) Are you prone to fear(s)? 3) Are you prone to depression? Whose response options in all cases were: a) Yes or b) No.

\section{Adult Attachment Styles Scale (AASS)}

Developed by Márquez et al. (2009), it comprises 21 items on a 7-point Likert-type scale that ranges from 1 totally disagree to 7 totally agree. People respond based on how they feel about each statement. The scale consists of three factors that represent the three types of attachment. The avoidant style consisted of 7 items and had a reliability index of $\alpha=.88$ (example: "It bothers me that my partner seeks a lot of closeness"). With 8 items, the anxious style had a reliability index of $\alpha=.86$ (example: "I am worried that my partner is not as interested in me as I am in her"). Finally, the secure style, with 6 items, had a reliability index of $\alpha=.81$ (example: "I trust that my partner loves me as much as I love her"). It is compared to the sum of the items that make up each of them and, the one with the highest score is interpreted as the predominance of the person's attachment style.

\section{Difficulties in Emotion Regulation Scale in Spanish (DERS-E)}

To assess ERD, a translated and adapted version of DERS (Gratz \& Roemer, 2004) was used (Marín et al., 2012). It is a self-report instrument designed to assess difficulties in emotional regulation. It consists of 24 items distributed in four factors. Non-acceptance, with 9 items and a reliability index $\alpha=.85$ (example: "I get angry with myself for feeling that way"). Goals, with 6 items and a re- 
liability index $\alpha=.79$ (example: "It's hard for me to do my homework"). Awareness, with 5 items and a reliability index $\alpha=.71$ (example: "My feelings are clear"). Clarity, with 4 items and a reliability index $\alpha=.68$ ("My emotions surpass me and they're out of control"). The reliability index of the 24 items was .89 . Each item is scored from 0 to 4 points; items 1, 2, 6, 7 and 9 are scored inversely. The total score is interpreted: below 14 points, it indicates low levels of difficulties in emotional regulation; between 15 and 31, it represents medium levels and, greater than 31 , high levels of difficulties.

\subsection{Procedure}

After having obtained the approval of the ethics committee of the Universidad de Colima, for the application of the scales, teachers of different subjects in different educational programs of higher-level (Bachelor's degree) authorized that during their class, the students would be invited to participate and thus, carry out a massive application in one go. The participants read the Informed Consent Form and those who consented in writing answer anonymously the scales (HSPS, AASS, and DERS-E) in an approximate time of 30 minutes.

\subsection{Data Analysis}

Data analysis was performed with the statistical program R 4.0.2 (R Core Team, 2020) with a $95 \%$ confidence level. Variance analysis, association analysis and generalized linear models were carried out with the psych package (Revelle, 2019), while the post hoc test was obtained with the agricolae package (de Mendiburu, 2019). The correlation matrix was obtained with the Hmisc package (Harrell Jr. \& Dupont, 2019) and structural equations with the lavaan package (Rosseel, 2012).

\section{Results}

\subsection{Attachment Styles and Neuroticism}

$86.6 \%$ of the participants showed a predominantly secure attachment style, 9.6\% an anxious attachment, and $3.7 \%$ an avoidant attachment. Regarding the neuroticism traits, $59.6 \%$ of the students saw themselves as tense or worried people, $50.8 \%$ described themselves as having a propensity to fear and $41 \%$ as depression. Only $22.7 \%$ of the participants answered negatively to the three questions. It should be noted that, within the anxious and avoidant attachment styles, were affirmative responses regarding the presence of neuroticism traits in more than half of the participants and, in the case of the secure style, $56.9 \%$ were described as a tense or worried person, $48.3 \%$ reported being prone to fear and $36.4 \%$ to depression.

\subsection{SPS and ERD Levels}

HSPS and DERS-E scores differed significantly from a normal distribution. Scores' differences of both scales were evaluated, taking into account gender, attachment 
style, and the presence of neuroticism traits. Results showed that women had a significantly higher SPS level than men did. Likewise, when participants described themselves with any of the three characteristics investigated concerning the neuroticism traits, the SPS levels were significantly higher. In addition, statistically significant differences were observed in SPS levels in relation to attachment styles. Those with a secure style had a significantly lower level than those with an anxious style and an avoidant style.

On the other hand, no statistically significant difference was found between the genders at the ERD level. This was significantly higher in participants who identified themselves as tense or worried people, prone to fear and depression, relative to those who did not. Finally, those with a secure attachment style had significantly lower ERD levels than those with an anxious style and an avoidant style. The participants with an avoidance style exhibited a significantly higher level of ERD than those with an anxious attachment.

\subsection{Correlations}

A correlation matrix was made to know the relationship between total levels of SPS, the total level of ERD and attachment styles. It is possible to notice in Table 1 that correlations between anxious and avoidant styles concerning SPS were weakly positive, unlike the secure style, where no correlation was presented. On the other hand, the correlation between ERD and SPS was positive and moderate.

Regarding correlations between attachment styles and ERD, the highest was presented with the anxious style. Likewise, the avoidant style correlated positively, although only weakly. On the contrary, the secure style had a weak negative correlation.

\subsection{Structural Equations}

Structural equation models (Loehlin \& Beaujean, 2017) were used to explore direct and indirect relationships between SPS, attachment styles, and ERD. Two models were examined: 1) attachment styles, SPS and ERD levels, and 2) attachment styles, SPS factors, and ERD factors.

Table 1. Correlation matrix between SPS, ERD, secure attachment, anxious attachment and avoidant attachment.

\begin{tabular}{cccccc}
\hline & SPS & ERD & SEC & ANX & AVO \\
\hline SPS & 1 & $.53^{* * *}$ & -.03 & $.37^{\star * *}$ & $.10^{\star *}$ \\
ERD & - & 1 & $-.23^{\star * *}$ & $.50^{\star * *}$ & $.20^{\star * *}$ \\
SEC & - & - & 1 & $-.10^{\star}$ & $-.38^{\star * *}$ \\
ANX & - & - & - & 1 & $.16^{\star * *}$ \\
AVO & - & - & - & - & 1 \\
\hline
\end{tabular}

Note: SPS = Sensory Processing Sensitivity total score; ERD = difficulties in emotional regulation total score; SEC = secure attachment; ANX = anxious attachment; AVO = avoidant attachment. ${ }^{\mathrm{a}} N=1040 .{ }^{\mathrm{b}} p<.05,{ }^{* *} p<.01,{ }^{* *} p<.001$. 
The first model results (Figure 1) showed that anxious attachment style is also indirectly related to the DRE through SPS. The second model found that avoidance style is indirectly related to NAC and CON (ERD factors) through LST (SPS factor). Furthermore, anxious attachment, it was indirectly related to the four factors of the ERD through both factors of the SPS (PS and LST). Table 2 shows adjustment values (Hooper et al., 2008) of the best models found.

\subsection{Differences in the Level of Difficulties in Emotional Regulation between Interactions (SPS Levels and Adult Attachment Styles)}

With the total scores obtained in the EPAS (minimum, maximum, first and third

Table 2. Adjustment values of $t$ models examined through structural equations analysis.

\begin{tabular}{|c|c|c|c|c|c|c|}
\hline & $\begin{array}{c}A G F I \\
\text { Adjusted goodness } \\
\text { of fit index }\end{array}$ & $\begin{array}{c}\text { AIC } \\
\text { Akaike } \\
\text { information } \\
\text { criterion }\end{array}$ & $\begin{array}{c}B I C \\
\text { Bayesian } \\
\text { information } \\
\text { criterion }\end{array}$ & $\begin{array}{c}C F I \\
\text { Comparative } \\
\text { Adjustment Index } \\
>\text { ó }=.90\end{array}$ & $\chi^{2}$ Model & $\begin{array}{c}\text { RMSEA } \\
\text { Root Mean } \\
\text { Square Error of } \\
\text { Approximation }<.08\end{array}$ \\
\hline Model 1 & .7561273 & $167,404.6$ & $167,904.3$ & .787 & 5914.841 & .064 \\
\hline Model 2 & -3.387953 & $38,014.01$ & 38,202 & .868 & 409.047 & .626 \\
\hline
\end{tabular}

Model 1

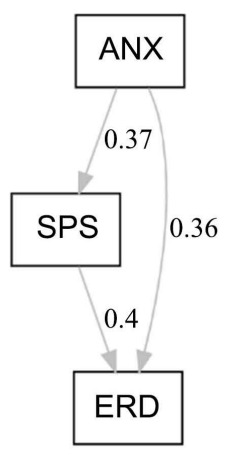

\section{Model 2}

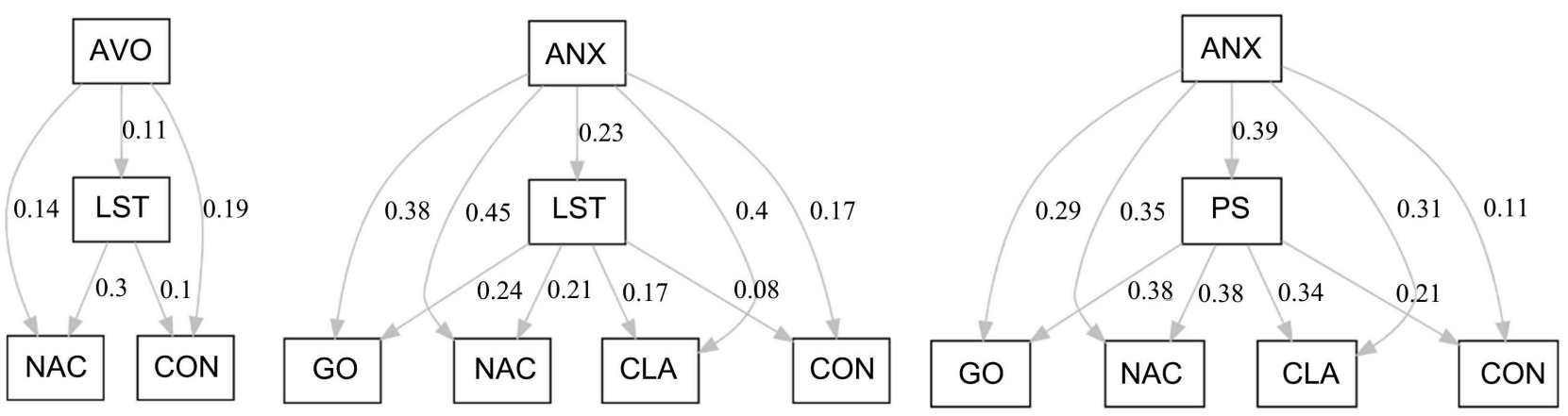

Figure 1. Mediation of SPS between attachment styles and difficulties in emotional regulation. SEC = secure attachment; $\mathrm{AVO}=$ avoidant attachment; ANX = anxious attachment; ERD = difficulties in emotional regulation total score; NAC = non-acceptance; $\mathrm{GO}$ = goals; CON = consciousness; CLA = clarity; SPS = sensory processing sensitivity total score; PS = processed sensitivity; LST = low sensitivity threshold. Only significant relationships between variables (direct and indirect) are included in the diagrams (with their estimated values). 
quartiles, mean and median), three levels of high sensitivity were determined: 1) Low, from 17 to 55 points; 2) Medium, from 56 to 81 points and; 3) High, from 82 to 119 points. Within the sample, 262 participants ( 140 women and 122 men) were located at the low level, 508 at the medium level (309 women and 199 men) and 270 at the high level (217 women and 53 men). It is important to mention that the medium level was not considered for the subsequent analyzes because it does not allow making the theoretical inferences necessary for the purposes of this study.

The differences in the total score of the DERS-E between six interactions (see Table 3) obtained from the combinations between the levels of SPS and the attachment styles were evaluated in order to test the hypotheses raised. For this, the Kruskal-Wallis analysis of variance was used, the results of which revealed statistically significant differences $(H(8)=328.49, p<.001)$.

Table 4 shows the stated hypotheses and the significance values obtained for each comparison, resulting from the post hoc test (multiple comparison).

\subsection{Generalized Linear Models}

Previous correlations revealed bivariate relationships between variables, and since the distribution of the DERS-E score was not normal and adjusted to a

Table 3. Interactions obtained from SPS levels and Attachment styles.

\begin{tabular}{ccc}
\hline & Nomenclature & Definition \\
\hline 1. & H-SPS * Secure & High level of SPS and Secure Attachment \\
2. & H-SPS * Anxious & High level of SPS and Anxious Attachment \\
3. & H-SPS * Avoidant & High level SPS and Avoidant Attachment \\
4. & L-SPS * Secure & Low level of SPS and Secure Attachment \\
5. & L-SPS * Anxious & Low level of SPS and Anxious Attachment \\
6. & L-SPS * Avoidant & Low level of SPS and Avoidant Attachment \\
\hline
\end{tabular}

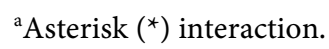

Table 4. Hypotheses and results of the post hoc test for the evaluation of the differences between the interactions (levels of SPS and attachment styles) with respect to the score of the Difficulties in Emotional Regulation Scale (DERS-E).

\begin{tabular}{cccc}
\hline Hypotheses & $\begin{array}{c}\text { Variance analysis } \\
\text { significance }\end{array}$ & $M$ & $S D$ \\
\hline H-SPS ${ }^{\star}$ Secure $<$ L-SPS ${ }^{\star}$ Secure & $\mathrm{p}<.0001$ & $40.34>19.02$ & $16.93<12.40$ \\
H-SPS $^{*}$ Anxious $>$ L-SPS Anxious & $p=.0108$ & $62.53>40.22$ & $16.24>14.91$ \\
H-SPS $^{*}$ Avoidant $>$ L-SPS Avoidant & $p=.0005$ & $55.53>24.00$ & $19.81>10.88$ \\
\hline
\end{tabular}

Note: H-SPS = SPS high level; L-SPS = SPS low level; Secure = secure attachment; Anxious = anxious attachment; Avoidant = avoidant attachment; $\mathrm{M}=$ mean; SD = standard deviation. ${ }^{a}$ Asterisk $\left({ }^{*}\right)$ interaction. ${ }^{b}(>)$ Greater than. ${ }^{c}(<)$ Less than. ${ }^{d}$ In bold statistically significant differences. ${ }^{e}$ In bold and italics statistically significant differences that reject the null hypothesis. 
gamma type, generalized log gamma linear models (Dunn \& Smyth, 2018) were evaluated to examine the relative contribution of these as predictors of difficulties in emotional regulation level (Table 5).

Results showed that SPS, attachment styles (secure, anxious, and avoidant), and SPS-attachment styles interactions, explained $42.6 \%$ of the variance. SPS, anxious attachment and, SPS-anxious attachment interaction were significant independent predictors of ERD. Considering the presence of neuroticism traits (tendency towards depression, fear, and considering oneself a tense or worried person), the same variables, with depression, explained $45 \%$ of the variance and contributed independently as predictors.

Likewise, the anxious attachment was the best predictor of ERD in both models. When neuroticism traits were taken into account, the tendency to depression was the only one that contributed significantly positively, subtracting weight from anxious attachment without being more significant.

It should be noted that SPS was a weak independent positive predictor in both models. However, only in interaction with anxious attachment contributed significantly, but negatively and weakly.

\section{Discussion}

This study aimed to analyze the relationship between SPS and attachment styles, with difficulties in emotional regulation (ERD) through: 1) evaluate the mediation of SPS between attachment style and ERD, 2) evaluate the differences in the level of ERD between SPS-attachment styles interactions and, 3) explore the role of SPS and attachment styles, as predictors of ERD.

In relation to the first subsection, structural equations analysis showed that avoidance style has indirect relationships with NAC and CON (ERD factors) through USB (SPS factor) and, that anxious style was indirectly related to all ERD factors (NAC, GO, CON, CLA) through both SPS factors (PS and LST). This could be explained, in part, by SPS multidimensionality, already been reported in other studies, especially when evaluating the relationship between the different dimensions of the SPS with variables associated with psychopathology

Table 5. Generalized linear models for SPS, attachment styles, and neuroticism traits as predictors of ERD.

\begin{tabular}{|c|c|c|c|c|c|c|c|c|c|c|c|}
\hline & SPS & Secure & Anxious & Avoidant & $\begin{array}{c}\text { SPS: } \\
\text { Secure }\end{array}$ & $\begin{array}{c}\text { SPS: } \\
\text { Anxious }\end{array}$ & $\begin{array}{c}\text { SPS: } \\
\text { Avoidant }\end{array}$ & $\begin{array}{c}\text { Tense or } \\
\text { worried person }\end{array}$ & $\begin{array}{l}\text { Tendency } \\
\text { to fear }\end{array}$ & $\begin{array}{l}\text { Depression } \\
\text { tendency }\end{array}$ & $\mathrm{R}^{2}$ \\
\hline ERD & $.026^{\star * *}$ & -.066 & $.310^{* * *}$ & .098 & -.001 & $-.002^{\star * *}$ & -.001 & & & & .426 \\
\hline $\begin{array}{l}\text { ERD and } \\
\text { NT }\end{array}$ & $.020^{* * *}$ & -.093 & $.286^{\star * *}$ & .103 & .000 & $-.002^{\star \star}$ & -.001 & .028 & .016 & $.215^{\star \star *}$ & .45 \\
\hline
\end{tabular}

Note: ERD = emotion regulation difficulties total score; NT = neuroticism trait; SPS = sensory processing sensitivity total score; Secure = secure attachment; Anxious = anxious attachment; Avoidant = avoidant attachment; SPS: Secure = SPS-Secure attachment interaction; SPS: Anxious = SPS-Anxious attachment interaction; SPS: Avoidant = SPS-Avoidant attachment interaction.

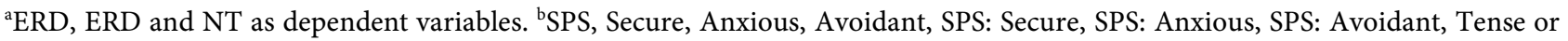
worried person, tendency to fear, depression tendency, as independent variables. ${ }^{c} \mathrm{R}^{2}$, explained variance. ${ }^{\mathrm{d} *} p<.05,{ }^{* *} p<.01$ and ${ }^{* * *} p<.001$. 
(e.g. Smolewska et al., 2006; Ahadi \& Basharpoor, 2010; Grimen \& Diseth, 2016). However, it is necessary to mention that unlike the HSPS original version, the HSPS Mexican version, used in this research, seems mainly focused on investigating the difficulties associated with SPS. Perhaps, for this reason, results showed a positive and moderate correlation of SPS with ERD as well as intermediation of SPS between ERD and insecure attachment, and not intermediation of SPS between ERD and secure attachment and a moderate negative correlation between SPS and ERD, as expected.

On the other hand, regarding subsection two, the analysis of variance with the Kruskal-Wallis test showed that the score obtained on the DERS-E, associated with the interactions between the high level of SPS and the attachment styles, differed significantly from that related to the interactions derived from the low level of SPS. In other words, participants with a high level of SPS, compared to those with a low level, had more difficulty regulating their emotions, regardless of the attachment style they show. This means that even students with a secure attachment and a high level of SPS reported more difficulties in regulating their emotions, compared to those who had the same attachment, but with a low level of SPS.

These results are in disagreement with what is proposed by Aron \& Aron (1997). Those with secure attachment and high SPS levels were expected to have significantly less difficulty regulating their emotions than those with low SPS levels and the same attachment style. This is due to the fact that secure attachment has been related to fewer difficulties in emotional regulation (e.g., Guzmán et al., 2016), and, in addition, people with high sensitivity tend to respond more intensely to emotional stimuli, especially positive ones (Jagiellowicz et al., 2016), benefiting from experiences that promote pleasant or pleasant emotions (Pluess \& Boniwell, 2015). Therefore, a high level of SPS coupled with a parenting with a secure attachment, could facilitate the development of more effective emotional regulation strategies.

However, what was obtained in this study could be in correspondence with what was stated by Liss et al. (2005). For these researchers, SPS seems to be an independent risk factor for experiencing psychological distress beyond experiences with parents, this because it is a physiological tendency to process information at low stimulation thresholds, which can predispose an individual to be more receptive and aware of possible threats in the environment and, therefore, be more physiologically reactive.

In this sense, the interaction between high level of SPS and attachment style seems to increase the probability of having difficulties in emotional regulation compared to a low level of SPS. When evaluating the differences in the level of difficulties in emotional regulation only among the attachment styles, it was found that students with secure attachment had significantly less difficulties than those with anxious or avoidant attachment, as has already been reported in the literature (e.g., Guzmán et al., 2016). 
Finally, on subsection tree, results show that SPS-anxious attachment interaction predicts ERD negatively and weakly. Similarly, the anxious attachment was the best predictor of ERD. Specifically, SPS-anxious attachment and SPS-avoidant attachment interactions were expected to yield an estimate with a positive value and, in the case of SPS-secure attachment interaction, a negative value. In other words, SPS-insecure attachment interaction (anxious and avoidant styles) would significantly increase the ERD level and, conversely, SPS-secure attachment interaction would decrease it. The results departed from these assumptions. However, they showed that SPS total level contributes significantly to ERD, although minimally, despite the moderate correlation between both variables.

Furthermore, depression tendency as the only significant predictor with a positive and second-best predictor of ERD only affects the anxious attachment contribution to ERD, but not the SPS value. Therefore, the correlation of SPS with ERD and anxious attachment, or its intermediation between it and ERD, seems unrelated to neuroticism traits or attachment style.

Consequently, even what was found in this study does not give empirical support to what Aron and Aron (1997) proposed and preferably, results coincide with what Liss et al., (2005), this research results have created an important precedent studying relationships between SPS, ERD, and adult attachment style for the first time.

Brindle et al. (2015) reported that emotional regulation difficulties mediate the relationship between SPS and negative affect, hypothesizing that this trait interferes with adaptive emotion regulation strategies is accompanied by a tendency to be exposed to negative and aversive internal states. However, it is known that these strategies are developed in the first years of life from the interaction with parents, who are at first, external regulators of the same (Thompson, 1994, 2014). Besides, these strategies are related to the attachment-behavioral systems activated by the experience of threats or stressors, internal or external (Mikulincer \& Shaver, 2016). It has been reported in various studies, correlations between attachment styles and levels of emotional regulation (e.g. Cabral et al., 2012; Pascuzzo et al., 2015; Guzmán et al., 2016). Hence, it was relevant to evaluate the attachment style in conjunction with SPS and emotion regulation difficulties.

Finally, as Ben-Avi et al. (2012) point out, it is very necessary that the SPS trait be evaluated in the clinical setting due to the implications it has in the development, treatment and prevention of psychopathology.

\section{Limitations}

The present study only used the three questions suggested by the authors of HSPS, original version, to determine the presence of neuroticism, which lacks psychometric support for this population. Also, the HSPS Mexican version has a possible bias in its structure, which seems focused on difficulties of high sensitivity experience without being able to collect other elements that potentially are 
also part of this trait and that would suppose benefits or advantages. Moreover, despite being numerous, the sample considered it is sufficiently homogeneous to limit external validity given that it was university students with little variability in age, education, and other demographic characteristics.

For this reason, in future research, it would be desirable to have an instrument to evaluate the positive or neutral aspects of SPS and make use of instruments with appropriate psychometric characteristics to evaluate neuroticism in the Mexican population. Similarly, a randomized and stratified sampling based on sociodemographic variables would allow for greater external validity.

\section{Conclusion}

Results suggest that the difficulties in regulating highly sensitive people's emotions are problematic to avoid, even with a secure attachment. However, HSPS Mexican version bias, when mainly evaluating SPS difficulties, does not allow the observing supporting effect of SPS-secure attachment interaction on emotional regulation.

This suggests reviewing the HSPS Mexican version and developing an instrument that manages to cover all the SPS aspects that theory contemplates and that indeed are not included in this scale. This will help future studies have greater clarity about SPS implications in interaction with attachment style and its relationship with emotion regulation strategies.

Similarly, it is necessary to consider other variables related to SPS and its interaction with environmental factors for the development or not of psychopathologies, such as parenting styles, social support, or resilience.

\section{Ethics Statement}

Approval of the ethics committee of the Universidad de Colima, January 2018.

\section{Conflicts of Interest}

The authors declared no potential conflicts of interest with respect to the research, authorship, and/or publication of this article.

\section{References}

Acevedo, B. (2020). The Basics of Sensory Processing Sensitivity. In B. Acevedo, (Ed.), The Highly Sensitive Brain (pp. 1-15). Academic Press. https://doi.org/10.1016/B978-0-12-818251-2.00001-1

Acevedo, B., Aron, E., Aron, A., Sangster, M., Collins, N., \& Brown, L. (2014). The Highly Sensitive Brain: An fMRI Study of Sensory Processing Sensitivity and Response to Others Emotions. Brain and Behavior, 4, 480-594. https://doi.org/10.1002/brb3.242

Acevedo, B., Jagiellowicz, J., Aron, E., Marhenke, R., \& Aron, A. (2017). Sensory Processing Sensitivity and Childhood Quality's Effects on Neural Responses to Emotional Stimuli. Clinical Neuropsychiatry, 6, 359-373.

Ahadi, B., \& Basharpoor, S. (2010). Relationship between Sensory Processing Sensitivity, Personality Dimensions and Mental Health. Journal of Applied Sciences, 10, 570-574. 
https://doi.org/10.3923/jas.2010.570.574

Aron, E. N., \& Aron, A. (2018, July 24). Tips for SPS Research. https://hsperson.com/wp-content/uploads/2018/08/Tips_for_SPS_Research_Revised_J uly24_2018.pdf

Aron, E., \& Aron, A. (1997). Sensory-Processing Sensitivity and its Relation to Introversion and Emotionality. Journal of Personality and Social Psychology, 73, 345-368. https://doi.org/10.1037/0022-3514.73.2.345

Aron, E., Aron, A., \& Davies, K. (2005). Adult Shyness: The Interaction of Temperamental Sensitivity and an Adverse Childhood Environment. Personality and Social Psychology Bulletin, 31, 181-197. https://doi.org/10.1177/0146167204271419

Aron, E., Aron, A., \& Jagiellowicz, J. (2012). Sensory Processing Sensitivity: A Review in the Light of the Evolution of Biological Responsivity. Personality and Social Psychology Review, 16, 262-282. https://doi.org/10.1177/1088868311434213

Ben-Avi, N., Almagor, M., \& Engel-Yeger, B. (2012). Sensory Processing Difficulties and Interpersonal Relationships in Adults: An Exploratory Study. Psychology, 3, 70-77. https://doi.org/10.4236/psych.2012.31012

Booth, Ch., Standage, H., \& Fox, E. (2015). Sensory-Processing Sensitivity Moderates the Association between Childhood Experiences and Adult Life Satisfaction. Personality and Individual Differences, 87, 24-29. https://doi.org/10.1016/j.paid.2015.07.020

Brindle, K., Moulding, R., Bakker, K., \& Nedeljkovic, M. (2015). Is the Relationship between Sensory-Processing Sensitivity and Negative Affect Mediated by Emotional Regulation? Australian Journal of Psychology, 67, 214-221. https://doi.org/10.1111/ajpy.12084

Cabral, J., Matos, P., Beyers, W., \& Soenens, B. (2012). Attachment, Emotion Regulation and Coping in Portuguese Emerging Adults: A Test a Mediation Hypothesis. The Spanish Journal of Psychology, 15, 1000-1012. https://doi.org/10.5209/rev_SJOP.2012.v15.n3.39391

de Mendiburu, F. (2019). Agricolae: Statistical Procedures for Agricultural Research. R Package Version 1.3-1. https://CRAN.R-project.org/package=agricolae

Dunn, P., \& Smyth, G. (2018). Generalized Linear Models With Examples in R. Springer-Verlag. https://doi.org/10.1007/978-1-4419-0118-7

Gratz, K. L., \& Roemer, L. (2004). Multidimensional Assessment of Emotion Regulation and Dysregulation: Development, Factor Structure, and Initial Validation of the Difficulties in Emotion Regulation Scale. Journal of Psychopathology and Behavioral Assessment, 26, 41-54. https://doi.org/10.1023/B:JOBA.0000007455.08539.94

Greven, C., \& Homberg, J. (2020). Sensory Processing Sensitivity-for Better or for Worse? Theory, Evidence, and Societal Implications. In B. Acevedo (Ed.), The Highly Sensitive Brain (pp. 51-74). Academic Press.

https://doi.org/10.1016/B978-0-12-818251-2.00003-5

Greven, C., Lionetti, F., Booth, Ch., Aron, E., Fox, E., Schendan, H., Pluess, M., Bruinin, H., Acevedo, B., Bijtterbier, P., \& Homberg, J. (2019). Sensory Processing Sensitivity in the Context of Environmental Sensitivity: A Critical Review and Development of Research Agenda. Neuroscience and Biobehavioral Reviews, 98, 287-305.

https://doi.org/10.1016/j.neubiorev.2019.01.009

Grimen, H., \& Diseth, A. (2016). Sensory Processing Sensitivity: Factors of the Highly Sensitive Person Scale and Their Relationships to Personality and Subjective Health Complaints. Comprehensive Psychology, 5, 1-10.

https://doi.org/10.1177/2165222816660077 
Guzmán-González, M., Carrasco, N., Figueroa, P., Trabucco, C., \& Vilca, D. (2016). Estilos de Apego y dificultades de Regulación Emocional en Estudiantes Universitarios. Psikhe, 25, 1-13. https://doi.org/10.7764/psykhe.25.1.706

Harrell Jr., F., \& Dupont, Ch. (2019). Hmisc: Harrell Miscellaneous. R Package Version 4.2-0. https://CRAN.R-project.org/package=Hmisc

Homberg, J., Schubert, D., Asan, E., \& Aron, E. (2016). Sensory Processing Sensitivity and Serotonin Gene Variance: Insights into Mechanisms Shaping Environmental Sensitivity. Neuroscience and Biobehavioral Reviews, 71, 472-483. https://doi.org/10.1016/j.neubiorev.2016.09.029

Hooper, D., Coughlan, J., \& Mullen, M. R. (2008). Structural Equation Modelling: Guidelines for Determining Model Fit. The Electronic Journal of Business Research Methods, 6, 53-60.

Jagiellowicz, J., Aron, A., \& Aron, E. (2016). Relationship between the Temperament Trait of Sensory Processing Sensitivity and Emotional Reactivity. Social Behavior and Personality, 44, 185-199. https://doi.org/10.2224/sbp.2016.44.2.185

Jagiellowicz, J., Xu, X., Aron, A., Aron, E., Cao, G., Feng, T., \& Weng, X. (2011). The Trait of Sensory Processing Sensitivity and Neural Responses to Changes in Visual Scenes. Social Cognitive and Affective Neuroscience, 6, 38-47.

https://doi.org/10.1093/scan/nsq001

Jagiellowicz, J., Zarinafsar, S., \& Acevedo, B. (2020). Health and Social Outcomes in Highly Sensitive Persons. In B. Acevedo (Ed.), The Highly Sensitive Brain (pp. 75-107). Academic Press. https://doi.org/10.1016/B978-0-12-818251-2.00004-7

Liss, M., Timmel, L., Baxley, K., \& Killingsworth, P. (2005). Sensory Processing Sensitivity and Its Relation to Parental Bonding, Anxiety, and Depression. Personality and Individual Differences, 39, 1429-1439. https://doi.org/10.1016/j.paid.2005.05.007

Loehlin, J. \& Beaujean, A. (2017). Latent Variable Models: An Introduction to Factor, Path, and Structural Equation Analysis (5th ed.). Routledge. https://doi.org/10.4324/9781315643199

Marín, M., Robles, R. González-Forteza, C., \& Andrade, P. (2012). Propiedades psicométricas de la escala "Dificultades en la Regulación Emocional” en español (DERS-E) para adolescentes mexicanos. Salud Mental, 35, 521-526.

Márquez, J., Rivera, S., \& Reyes, I. (2009). Desarrollo de una escala de estilos de apego adulto para la población mexicana. Revista Iberoamericana de Diagnóstico y Evaluación, $28,9-30$.

Mikulincer, M. \& Shaver, P. (2012). An Attachment Perspective on Psychopathology. World Psychiatry, 11, 11-15. https://doi.org/10.1016/j.wpsyc.2012.01.003

Mikulincer, M., \& Shaver, P. (2016). Attachment in Adulthood. Guilford Press.

Montoya-Pérez, K. S., Ortega, J.I.M., Montes-Delgado, R., Padrós-Blázquez, F., de la Roca Chiapas, J. M., \& Montoya-Pérez, R. (2019). Psychometric Properties of the Highly Sensitive Person Scale in Mexican Population. Psychology Research and Behavior Management, 12, 1081-1086. https://doi.org/10.2147/PRBM.S224808

Naumann, F., Acevedo, B., Jagiellowicz, J., Greven, C., \& Homberg, J. (2020). Etiology of Sensory Processing Sensitivity: Neurobiology, Genes, and Evolution. In B. Acevedo (Ed.), The Highly Sensitive Brain (pp. 109-134). Academic Press. https://doi.org/10.1016/B978-0-12-818251-2.00005-9

Pascuzzo, K., Moss, E., \& Cyr, Ch. (2015). Attachment and Emotion Regulation Strategies in Predicting Adult Psychopathology. SAGE Open, 5, 1-15.

https://doi.org/10.1177/2158244015604695 
Pluess, M., \& Boniwell, I. (2015). Sensory-Processing Sensitivity Predicts Treatment Response to a School-Based Depression Prevention Program: Evidence of Vantage Sensitivity. Personality and Individual Differences, 82, 40-45.

https://doi.org/10.1016/j.paid.2015.03.011

R Core Team (2020). R: A Language and Environment for Statistical Computing. R Foundation for Statistical Computing. https://www.R-project.org/

Rehm, I., \& Staiger, P. (2018). Emotion Regulation and Psychopathology: Current Understanding and New Directions. Clinical Psychologist, 22, 109-111.

https://doi.org/10.1111/cp.12164

Revelle, W. (2019). Psych: Procedures for Psychological, Psychometric, and Personality Research. R Package Version 1.9.12, Northwestern University. https://CRAN.R-project.org/package=psych

Rosseel, Y. (2012). Lavaan: An R Package for Structural Equation Modeling. Journal of Statistical Software, 48, 1-36. https://doi.org/10.18637/jss.v048.i02

Slagt, M., Dubas, J., van Aken, M., Ellis, B., \& Dekovic, M. (2017). Sensory Processing Sensitivity as a Marker of Differential Susceptibility to Parenting. Developmental Psychology, 54, 543-558. https://doi.org/10.1037/dev0000431

Sloan, E., Hall, K., Moulding, R., Bryce, S., Mildred, H., \& Staiger, P. (2017). Emotion Regulation as a Transdiagnostic Treatment Construct across Anxiety, Depression, Substance, Eating and Borderline Personality Disorders: A Systematic Review. Clinical Psychology Review, 57, 141-163. https://doi.org/10.1016/j.cpr.2017.09.002

Smolewska, K., McCabe, S., \& Woody, E. (2006). A Psychometric Evaluation of the Highly Sensitive Person Scale: The Components of Sensory-Processing Sensitivity and Their Relation to the BIS/BAS and "Big Five". Personality and Individual Differences, 40, 1269-1279. https://doi.org/10.1016/j.paid.2005.09.022

Thompson, R. (1994). Emotion Regulation: A Theme in Search of Definition. Monographs of the Society for Research in Child Development, 59, 25-52. https://doi.org/10.1111/j.1540-5834.1994.tb01276.x

Thompson, R. (2014). Socialization of Emotion and Emotion Regulation in the Family. In J. Gross (Ed.), Handbook of Emotion Regulation (2nd ed., pp. 173-186). The Guilford Press. 